\title{
Hybrid Fuzzy-PID based MPPT Enhancement of Grid-Connected DFIG Wind Energy System with TLBO Optimization
}

\author{
Sachin Bhati ${ }^{\mathrm{a}}$, Prerna Gaur ${ }^{\mathrm{a}}$ \\ anstrumentation and Control Engineering department \\ ${ }^{a}$ Netaji Subhas University of Technology, New Delhi 110078, India
}

\begin{abstract}
This research article emphasizes the enhancement of Maximum Power Point Tracking (MPPT) action using a Fuzzy supervised PID (f-PID) controller for a grid-connected 2MW Doubly fed Induction Generator (DFIG) connected to a passive filter and grid via Back-to-Back PWM Converter topology. This article also proposes the implementation of Teaching Learningbased optimization (TLBO) technique for tuning gain parameters of the proposed as well as extant controllers used in the MPPT algorithm. The primary objective is to improvise the conventional Rotor side current-based field-oriented control (MSC) of the understudy system, by employing a modified TipSpeed Ratio (TSR) based MPPT algorithm with wind speed estimator. This algorithm ensures extraction and regulation of maximum active power while minimizing stator reactive power drawn under a step-wise variable wind speed profile. It is realized by employing a PID controller to restrict rotor angular speed variation around its optimal value, estimated by a fuzzy logic system. After the completion of a comprehensive simulation analysis using MATLAB/Simulink R2017a, the performance of the proposed controller in steady as well as transient states is being fairly found to be superior as compared to that of PID and Non-linear PID (NPID) based controllers in terms of settling time, MPP steady-state error and tracking efficiency.
\end{abstract}

Keywords- Maximum Power Point Tracking (MPPT), Fuzzy supervised PID, doubly fed Induction Generator (DFIG), Machine side control (MSC), Tip-Speed Ratio (TSR), Teaching-Learning Based Optimization (TLBO)

\section{INTRODUCTION}

Wind energy is one of the few standouts amongst the most appealing renewable energy power source on account of its high extraction efficiency and low environmental contamination. Wind energy is one of the few standouts amongst the most appealing renewable energy power source on account of its high extraction efficiency and low environmental contamination. Besides being always accessible in most parts of the planet, the production cost/kWh of Wind energy conversion system (WECS) is much lower than that of any other solar-based energy source [1].In the last 40 years, WECS is being developed not only on quantitative but also on the functionality front. Branching out from being a fossil fuelalternative technology, it has also found beneficial roles in grid stabilization and black start technologies. Consequently, research and development of WECS in India have been focused on all aspects, ranging from component design using site assessment and improvisation in control and maintenance technology. As of October $2019,10 \%$ or $36,686.82 \mathrm{GW}$ of total operational electric generation capacity utilizes wind energy sources, making India 4th. Largest wind-based electricity generation country in the world.

Among the several options of aerogenerators, DFIGs are proven to be the most commercial and academic preferential option due to the application of partial-rated power converters [2]. Some of the recent advancements relevant to MPPT algorithms with these aerogenerators can be reviewed. An improved variable step Hill-Climbing search (HCS) algorithm [3] and hybrid sectors-based Perturbation \& Observation (PSO) [4] are some of the most extensively used for MPPT action in the field due to simplicity in implementation to find optimal wind turbine control parameters. A variable HCS algorithm eliminates the drawbacks of conventional HCS with large oscillations around MPP, but in turn, becomes largely dependent on generator parameters. $\mathrm{P} \& \mathrm{O}$ technique has the limitation of requiring optimal power-speed curve of generator. [5] has implemented non-linear backstepping control technique to design MPPT scheme for a DFIG-based WECS. However, this control requires the understanding of the system's dynamic model for the training data [6]. Considering all the shortcomings listed above and due to complex nature of these advanced soft computing techniques to implement, a simple AI based MPPT algorithm with high tracking performance seems to be more feasible to implement in field.

Tip-Speed Ratio (TSR) control is among the most popular MPPT techniques to determine the optimum value of system variables due to its ease of implementation and high tracking performance. However, [7] indicates that TSR control has higher response time and overall efficiency among very limited options under this category. To achieve the least steady-state response, several types of conventional controllers are already being analyzed in the literature. The utilization of PID controllers for MPPT action, especially under turbulent wind conditions is not feasible to provide satisfactory performance [8].

Fuzzy based MPPT techniques are preferable for such highly non-linear systems. Abdelmalek et. al. [9] has proposed the transformation of non-linear DFIG into equivalent TakagiSugeno (TS) fuzzy model. However, the advantage of Mamdani inference technique over the TS is unquestionable, which lies in its unique ability to use not only numerical but also linguistic data obtained from system knowledge and experience [10]. Recently, type-2 fuzzy logic [11] are becoming popular by replacing rotor current conventional controls. However, using of uncertainty probabilistic functions instead of crisp sets results in complex control to implement. 
Adaptive neuro-fuzzy (ANFIS) control in [12], [13] are also in trend, however, besides of requiring a large volume of data like variation of rotor angular speed a, TSR values concerning variation in wind speed to train Artificial neural network (ANN), it also suffers from the bounded output limitation of fuzzy logic. Artificial Bee Colony (ABC) based MPPT [14] is one of the cutting-edge advancements in this sector, which is proven to an effective and most accurate, yet complex to realize.

There are several AI-based optimization techniques applied for assigning gains of conventional controllers employed in MPPT, including PSO [15], [16], Greywolf [17] and Linearized Biogeography-Based Optimization (LBBO-DE) [18] where the complexity of the approach and computational sensor requirement are among the key factors in deciding on the technique to be implemented.

After a thorough analysis of the literature survey, before building the simulation, it was obvious that there is a requirement of modified TSR-based MPPT control, which while retaining its simple configuration, allows industries to retrofit modification to the existing control module to enhance MPPT performance. This article is based upon the Tip-Speed ratio (TSR) based MPPT algorithm in which the tip speed ratio (and hence the rotor angular speed for specific wind velocity) is controlled to its optimal value to ensure MPPT action.

Non-linear PID (NPID) and Fuzzy supervised PID are upgraded configurations of conventional PID and fuzzy logic control employed in MPPT algorithm to adjust tip speed ratio to its optimum for an estimated value of wind velocity. The major contributions of the present work can be listed as follows:

1. NPID and Fuzzy supervised PID controllers are proposed to enhance the performance of TSR MPPT action for a 2MW grid-connected DFIG based WECS.

2. The conventional Rotor side control (RSC) method is modified using an improved SPWM controller with third harmonic injection for THD suppression and equation-based wind speed estimator to eliminate the disadvantage of anemometer requirement causing inaccurate response.

3. A comparative analysis of MPPT methods is being carried out to verify the performance superiority of proposed controllers over other conventional methods like PID based MPPT methods.

4. Optimal tuning gain parameters of proposed and extant MPPT methods using the TLBO (Teaching-Learning based optimization) technique.

The research work under this article is being presented under the following headers: a comprehensive literature review in section 1, the mathematical modeling of WECS in section 2. Section 3,4 \& 5 discusses the concept of the extant and proposed TSR MPPT methods. The tuning method of proposed and other MPPT methods is discussed in section 6 . The obtained simulation results are investigated and discussed for the MPPT under the different wind profiles in Section 7. Finally, Section 8 discusses the conclusions drawn from the case study.

\section{SYSTEM DESCRIPTION}

A variable speed grid-connected DFIG based WECS with partial rated back-to-back converters topology (refer Fig. 1), can be divided into following interdependent subsystems:

1. Wind turbine

2. Electrical subsystem

3. Transmission Network \& Utility grid

Each subsystem is now being discussed briefly within the scope of the case study for understanding the dynamic modeling and functionality of each subsystem.

\section{A. Wind Turbine}

A wind turbine is a mechanical device that utilizes wind flow to extract the kinetic energy and transfer it to the generator shaft in the form of mechanical energy. The Mechanical power captured by the wind machine is given by [19]:

$$
\mathrm{P}_{\mathrm{m}}=\frac{1}{2 N} \rho A v_{w}^{3} C_{p}(\lambda, \beta)
$$

where blade swept area $\mathrm{A}=\pi \mathrm{R}^{2}, \mathrm{R}$ is the turbine blade length and performance coefficient $\mathrm{Cp}$ is given by:

$$
\mathrm{C}_{\mathrm{p}}(\lambda, \beta)=0.22\left(\frac{116}{\lambda_{i}}-0.4 \beta-5\right) e^{-\frac{12.5}{\lambda_{i}}}
$$

Where intermediate constant $\lambda_{\mathrm{i}}$ is determined by:

$$
\frac{1}{\lambda_{i}}=\frac{1}{\lambda+0.08 \beta}-\frac{0.035}{\beta^{3}+1}
$$

and Tip speed ratio (TSR) as:

$$
\lambda=\frac{\left(\omega_{m} / N\right) R}{v_{w}}
$$

The pitch angle $(\beta)$ for the understudy system is kept at zero as the proposed MPPT control is valid only between cut-in and cut-out wind speed, i.e. generator output power never goes beyond its rated value.

\section{B. Electrical Subsystem}

The electrical subsystem of a variable speed, gridconnected DFIG based WECS consists of an airborne threephase DFIG, which is a doubly-excited generator with stator winding feeding active power directly to grid. The rotor winding of the generator is indirectly connected to the grid via a partial rated Rotor side converter, which is rated normally to $30 \%$ of the wind turbine rating, making this configuration attractive for WECS designers from the cost point of view. The Rotor side control enables the regulation of active and reactive power flow by controlling rotor angular speed. The Grid side converter enables power quality management by synchronizing rotor power to the grid level at constant dc-link voltage and frequency [17]. A three-phase non-linear passive filter is generally used in the rotor circuit before feeding the power to the utility grid with further reduced harmonics. 


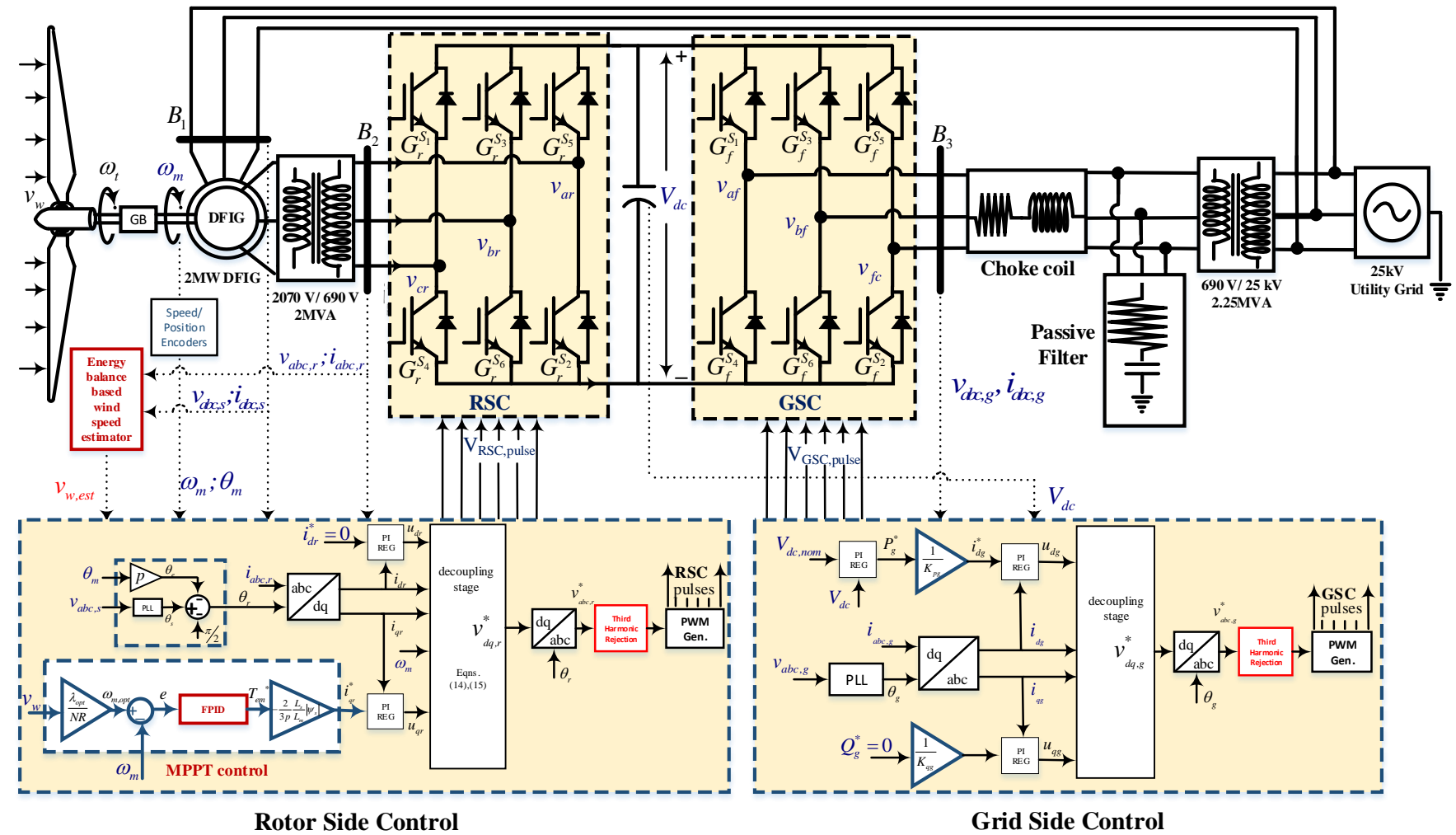

Fig. 1. DFIG based grid-connected understudy system

The dynamic model of DFIG in an arbitrary d-q reference frame voltage and current can be represented using equation (5)-(12) [20]:

$$
\begin{aligned}
& \mathrm{v}_{\mathrm{ds}}=r_{s} i_{d s}+\frac{d \Psi_{d s}}{d t}-p \omega_{s} \Psi_{q s} \\
& \mathrm{v}_{\mathrm{qs}}=r_{s} i_{q s}+\frac{d \Psi_{q s}}{d t}+p \omega_{s} \Psi_{d s} \\
& v_{\mathrm{dr}}=r_{r} i_{d r}+\frac{d \Psi_{d r}}{d t}-p \omega_{m} \Psi_{q r} \\
& \mathrm{v}_{\mathrm{qr}}=r_{r} i_{q r}+\frac{d \Psi_{q r}}{d t}+p \omega_{m} \Psi_{d r}
\end{aligned}
$$

Where $r_{s}, L_{s}$, and $r_{r}, L_{r}$ are stator and rotor resistance and inductance values respectively. Flux linkages are given as:

$$
\begin{aligned}
& \Psi_{\mathrm{ds}}=L_{s} i_{d s}+L_{m} i_{d r} \\
& \Psi_{\mathrm{qs}}=L_{s} i_{q s}+L_{m} i_{q r} \\
& \Psi_{\mathrm{dr}}=L_{r} i_{d r}+L_{m} i_{d s} \\
& \Psi_{\mathrm{qr}}=L_{r} i_{q r}+L_{m} i_{q s}
\end{aligned}
$$

The expression electromagnetic torque of DFIG can be expressed as:

$$
T_{e m}=p\left(\Psi_{d s} i_{q s}-\Psi_{q s} i_{d s}\right)
$$

Irrespective of the mode of operation, stator winding active power remains unaffected. However, an MSC control enables the regulation of rotor active and reactive power flow through the generator by controlling rotor speed $\omega_{\mathrm{m}}$. It is crucial to run the generator at super-synchronous speed mode, as in this case rotor active power is fed into the grid while reactive power is being supplied to the generator, resulting in better efficiency throughout the operation. For this purpose, an MPPT controller is used to generate reference rotor q-axis current, ${ }^{2}$ mref, which is then used to control the rotor quadrature axis current using a tuned PI Controller. The reference three-phase rotor voltage for PWM generator is determined by the decoupling equation derived from the DFIG dynamic model and are expressed as [20]:

$$
\begin{gathered}
v_{d r}^{*}=u_{d r}-\omega_{r} \sigma L_{r} i_{q r} \\
v_{q r}^{*}=u_{q r}+\omega_{r} \sigma L_{r} i_{d r}+\omega_{r} \frac{L_{m}}{L_{\text {gr }}}\left|\Psi_{s}\right|
\end{gathered}
$$

Where $u_{d r}, u_{q r}$ are the linear approximations of the direct and direct derivative terms in terms of rotor currents, $\mathrm{p}$ is the no. of pole pair, rotor angular speed 11$) \omega_{r}=\omega_{s}-p \omega_{m}$, $\sigma=1-\frac{L_{m}^{2}}{L_{s} L_{r}}$ is the leakage coefficient, and $\left|\psi_{s}\right|$ is the reference stator flux.

Besides ensuring unity power factor of the grid current throughout operation, Grid side converter (GSC) control is 
also used to provide synchronism between GSC output terminal and the grid by controlling active and reactive power fed to the load with constant grid bus voltage. A grid-side system consists of a DC-link Capacitor, a 3-phase partially scaled VSC, and shunt passive and series RL-based filters. For unity power factor operation, the d-axis grid voltage should be perfectly aligned along with the DC-link capacitor voltage, i.e. the q-axis synchronized grid voltage must become zero. To minimize reactive power inflow to the machine, the reference reactive power $\left(\mathrm{Q}_{\mathrm{g}}{ }^{*}\right)$ is set to zero [21]. To satisfy both criteria, a cascade control is implemented with the outer loop controlling DC-link voltage to the reference setpoint of $1150 \mathrm{~V}$, whose control output is fed to the inner $i_{d}$ current control loop.

THD of the DFIG system terminal current depends upon the amplitude of the first harmonic component. Hence, appropriate transformation is required before feeding reference voltages to a 3-phase PWM pulse generator. The first harmonic component can be amplified by reducing the third harmonic component of the RSC output voltage without power quality loss. Hence, a reference signal is injected with the third harmonic component. It is a common practice to realize third harmonic injection along with conventional SPWM by following the expression [24]:

$$
V_{3}=-\frac{\max \left(u_{a b c}\right)+\min \left(u_{a b c}\right)}{2}
$$

The generated power after being synchronized to the grid is finally fed to the utility grid after having its voltage stepped up from $690 \mathrm{~V}$ to $25 \mathrm{kV}$, which is the rated voltage at the grid bus, using a 3-phase Y- $\Delta$ transformer.

\section{MPPT CONTROL TECHNIQUES}

For any variable-speed WECS, the stator active power generation varies along with the change in wind speed. For unique wind speed, there exists exactly one optimum tip speed ratio (TSR), and hence a unique rotor speed $\omega_{m}$ opt, at which, maximum stator active power can be generated by controlling the flow of slip power through the rotor side converter (RSC). The RSC MPPT control model is hence, designed to regulate the rotor speed close to $\omega_{m_{-} \text {opt }}$ for optimal tracking of maximum power point at a specific wind speed (as shown in Fig. 2). This optimization technique implemented in MSC control.

One of the major drawbacks of this control algorithm is the physical need of an anemometer, which is generally placed at the back-end of the nacelle. This position is very far from the blades in a large-scale onshore wind energy system causing moderately inaccurate and sluggish wind velocity measurement. Hence, in this case study, the TSR based MPPT technique is being modified by using a wind speed estimator block.

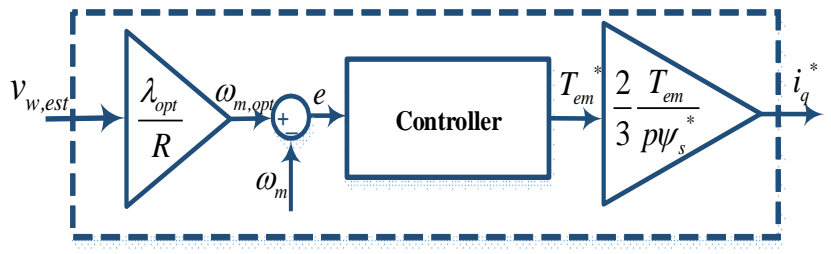

Fig. 2. TSR based MPPT algorithm with estimated wind velocity

\section{A. Wind speed estimation}

As a conventional anemometer is always placed at the head of the nacelle of wind turbine tower, the measurement of wind velocity, the intersecting blade is always moderately inaccurate. Besides, the presence of physical sensors makes the MPPT action sluggish. Hence, the physical sensor is being replaced by an estimator which requires the electrical quantities related to the generator.

The electromagnetic power of the generator can be expressed as:

$$
P_{e}=P_{m}-\sum P_{\text {losses }}
$$

Where, $\quad P_{e}=v_{s d} i_{s d}+v_{s q} i_{s q}+v_{r d} i_{r d}+v_{r q} i_{r q}$

with losses $\sum P_{\text {losses }}=P_{j s}+P_{j r}+P_{i r}+P_{f r}$. Neglecting rotor iron loss $P_{i r}$, the total power loss can be computed as follows:

Joule Loss: $P_{j s}+P_{j r}=R_{s}\left(i_{s d}{ }^{2}+i_{s q}{ }^{2}\right)+R_{r}\left(i_{r d}{ }^{2}+i_{r q}{ }^{2}\right)$

Friction losses:

$$
P_{f r}=D \omega_{m}^{2}
$$

Using (16)-(19), we can obtain the estimated value of wind speed as [22]:

$$
v_{w, e s t}=\sqrt[3]{\frac{2\left(P_{e}+\sum P_{\text {losses }}\right)}{\rho \pi R^{2} C_{p}}}
$$

\section{EXTANT MPPT SCHEMES}

To analyze and verify the crucial role of the proposed controller employed in the proposed MPPT algorithm, a performance comparison is carried out using the conventional and improved version of the conventional controller. A brief discussion on both classes of controllers is provided in the following sections:

\section{A. PID Controller}

With the variation in wind speed, the MPP power reference for the WECS varies as well. A discrete-time PID controller with fixed gains regulates the instantaneous value of rotor mechanical speed to its reference value by processing the error between two, following the control output transfer function stated as [23]:

$$
u_{P I D}(z)=\left(k_{p}+\frac{k_{i} T_{s}}{z-1}+\frac{k_{d}(z-1)}{T_{s} z}\right) e
$$

Where e is the error, along proportional gain $\mathrm{k}_{\mathrm{p}}$, integral gain $\mathrm{k}_{\mathrm{i}}$, and sampling time $\mathrm{T}_{\mathrm{s}}$ for the used discrete PID controller. The controller gains are tuned using the optimization technique discussed in the later section. The sampling time for the model, in general, can be determined using switching frequency $f_{s w}$, grid operating frequency $f_{g}$, and relation:

$$
T_{s}=\frac{1}{f_{g} f_{s w}}
$$




\section{PROPOSED MPPT SCHEMES}

In this research paper, Non-linear PID (NPID) and fuzzy supervised PID (f-PID) based TSR-MPPT algorithms are proposed, where each controller deals with the limitations of extant PID based MPPT performance in a unique way. While NPID deals with poor MPPT action by considering the nonlinear nature of error before applying integral gain response, $\mathrm{f}$ PID eliminates the impractical necessity of assuming constant TSR while designing discussed MPPT controller. The simulation analysis performed in the later section reveals that this method results in the convergence of operating point to MPP with higher accuracy and robustness for any non-linear automation plant like WECS.

\section{A. Non-Linear PID controller}

With abrupt variation in the wind speed, the sluggish response of the proposed technique with PID controller along with large overshoot around the transient regions of wind speed profile is observed in many pieces of literatures [15]. One of the main causes of such response is due to the fixed integral gain of the conventional PID controller, causing lagging control output when such large error change is experienced. The Non-linear PID (NPID) controller is designed with the main focus on adaptive Integral response, which is influenced by the magnitude of error change. The control output transfer function of the above PID controller is modified and uses in the given form:

$$
u_{N P I D}(z)=\left(k_{p}+\frac{k_{i} T_{s}}{z-1} k(e)+\frac{k_{d}(z-1)}{T_{s} z}\right) e
$$

Where $\mathrm{kp}$, $\mathrm{ki}$ are tuned proportional and integral gains respectively. $\mathrm{k}(\mathrm{e})$ is a non-linear error function represented as [24]:

$k(e)=\cosh \left(k_{o} e\right)=\frac{\exp \left(k_{o} e\right)+\exp \left(-k_{o} e\right)}{2}$

\section{B. Fuzzy Supervised PID controller}

The proposed fuzzy-supervised MPPT controller as shown in Fig. 3 uses an FLC-based algorithm with inputs:

(1) The error between optimal and actual generator speed $(e)$

(2) rate of change of error $(\Delta e)$ [25]

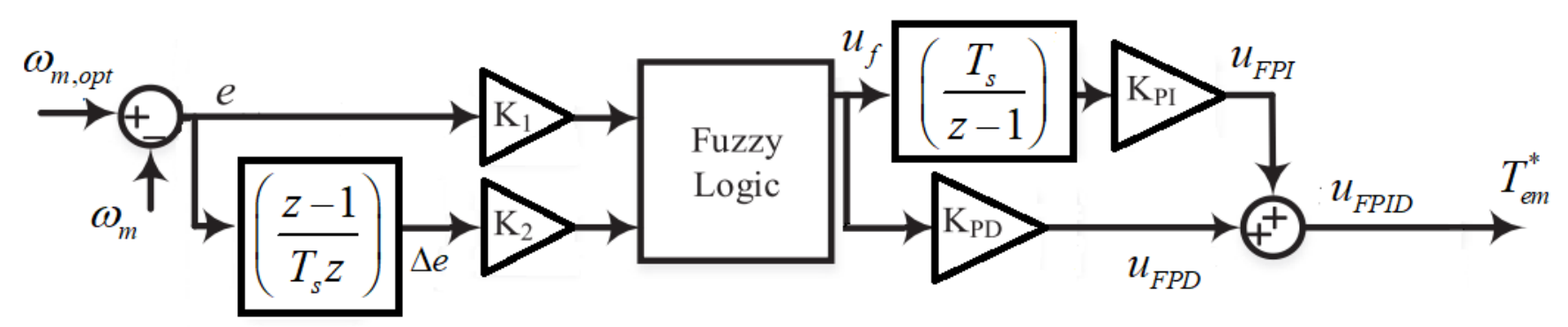

Fig. 3. Fuzzy Supervised PID MPPT Controller
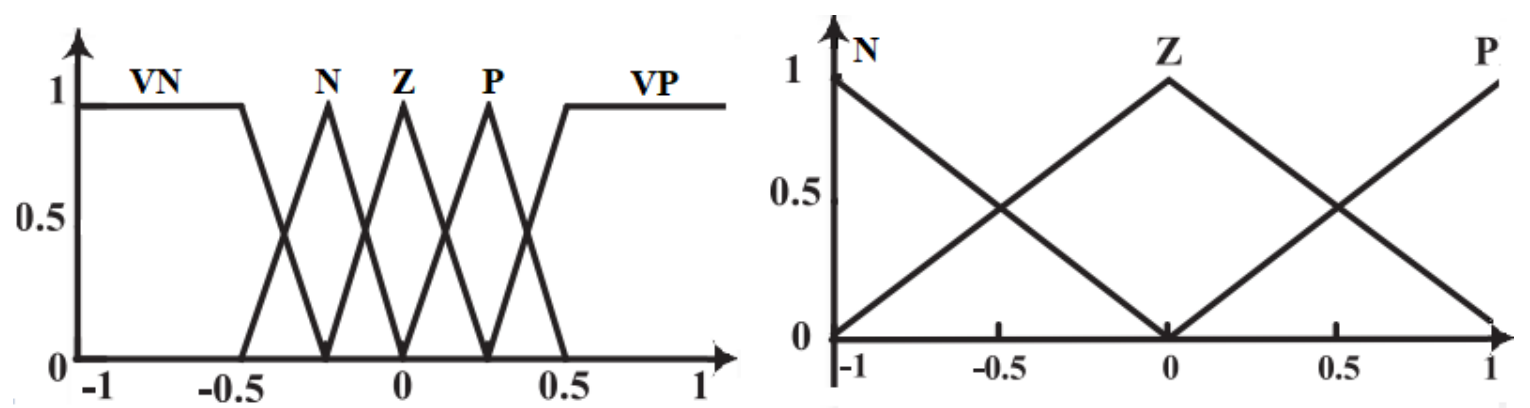

(b)

\begin{tabular}{cccccc}
\hline & $e$ & & & & \\
\cline { 2 - 6 }$\Delta e$ & $\mathbf{V N}$ & $\mathbf{N}$ & $\mathrm{Z}$ & $\mathrm{P}$ & $\mathbf{V P}$ \\
\hline $\mathbf{N}$ & $\mathbf{V N}$ & $\mathbf{V N}$ & $\mathrm{N}$ & $\mathrm{Z}$ & $\mathrm{P}$ \\
$\mathrm{Z}$ & $\mathbf{V N}$ & $\mathrm{N}$ & $\mathrm{Z}$ & $\mathrm{P}$ & $\mathrm{P}$ \\
$\mathrm{P}$ & $\mathrm{N}$ & $\mathrm{Z}$ & $\mathrm{P}$ & $\mathbf{V P}$ & $\mathbf{V P}$ \\
\hline
\end{tabular}

(c)

Fig. 4. Membership function of (a) error in generator speed and output (b) change in error between optimum and actual rotor speed (c) rule base for the proposed fuzzy-supervised PID based MPPT controller 


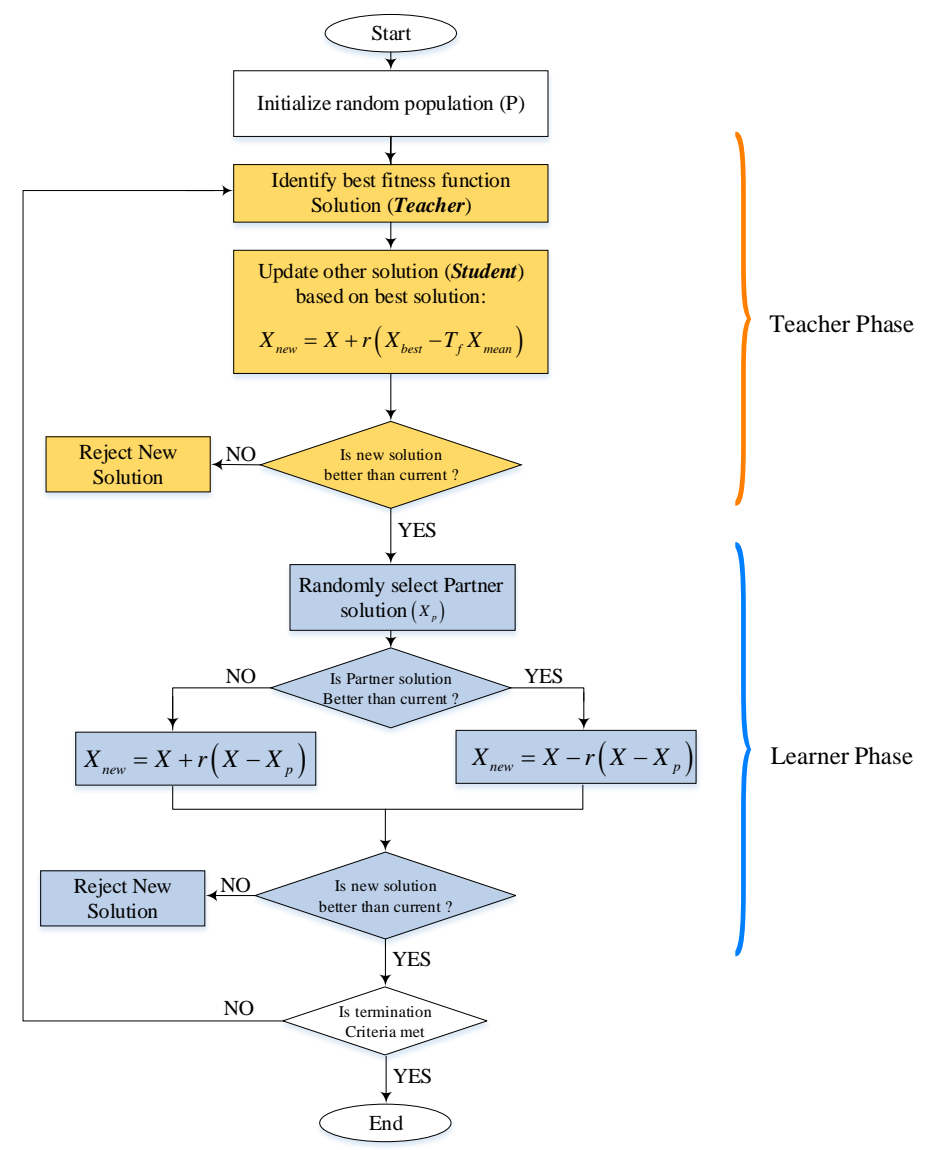

Fig. 5. TLBO flowchart

The output of FLC is then fed to a PI and PD based controller (fuzzy PI + PD = fuzzy PID based controller) which results in the final output of reference torque $\left(T_{e m}^{*}\right)$. The Fuzzy membership values along with the rule base are shown in fig. 4. with linguistic variables: Very negative (VN), Negative (N), Zero (Z), Positive (P), and Very Positive (VP).

\section{TUNING OF MPPT CONTROLLERS}

TLBO is one of the modern metaheuristic optimization techniques, primitively developed for the optimization of constrained mechanical design in 2011. The algorithm is segregated into two phases: a Teacher phase under which randomly initiated population's $i^{\text {th }}$ solution (student) is updated based on the mean solution $\left(X_{\text {mean }}^{i}\right)$ and best fitness value solution (teacher, $X_{\text {best }}^{i}$ ) as per the equation stated below:

$$
X_{\text {new }}^{i}=X^{i}+r\left(X_{\text {best }}^{i}-T_{f} X_{\text {mean }}^{i}\right)
$$

where $r$ is a random number (between 1 or 2) and $T_{f}$ is called teaching factor, taken constant as 1 or 2 for one teachinglearning cycle. In case the fitness function value of the new solution is lower than the existing one, the existing one is replaced by the new student using greedy selection technique. The Learner phase is initiated by selecting a random partner solution $\left(X_{p}^{i}\right)$. On the basis of the random partner and current solution's fitness function value, the updated solution under the learner phase is express by:

$$
X_{\text {new }}^{i}=X^{i}+r\left(X^{i}-X_{p}^{i}\right) ; \text { for } f\left(X^{i}\right)<f\left(X_{p}^{i}\right)
$$

or

$X_{\text {new }}^{i}=X^{i}+r\left(X^{i}-X_{p}^{i}\right) ; f\left(X^{i}\right)>f\left(X_{p}\right)$

where $f$ is the cost function of the TLBO algorithm. In case the determined new solution fitness function value is found to be lesser than that of existing solution, the new solution replaces the existing solution in the population The whole teaching-learning cycle is then repeated for all other students till either maximum number of iterations are reached or the termination criteria is met by the end solution of certain iteration. Fig. 5 summarizes the above discussion in the form of a detailed flowchart for TLBO implementation [26].

The learner cost will be affected only if the cost of other learners in the population is more than that of itself. This statement is formulated as: 


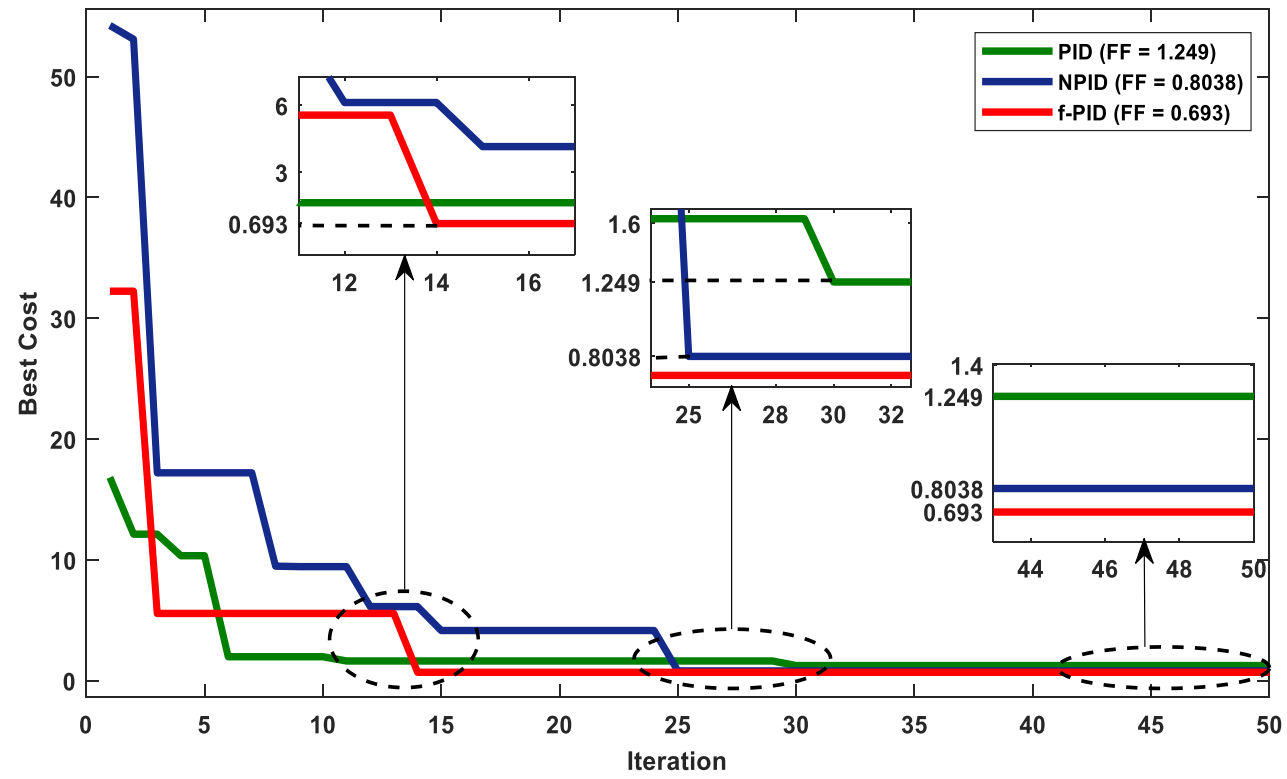

Fig. 6. TLBO Optimization curve with fitness value (FF) for each iteration

The cost function for the simulation is based upon the weighted sum of the integral of squared error (ISE) and integral of time-weighted absolute error (ITAE), where the error is based upon the normalized reference and instantaneous WECS rotor angular speed. ISE decreases the settling time by eliminating minor errors around the reference value whereas ITAE minimizes the major errors caused by spontaneous and sudden irradiation level variation by regulating transient oscillations. The fitness function (FF) used to compute solution cost is formulated as:

$F F=a_{1} \cdot\left[\int_{0}^{t}[e(t)]^{2} d t\right]+a_{2} \cdot\left[\int_{0}^{t} t \cdot|e(t)| d t\right]$

\section{SIMULATION ANALYSIS}

The case study under this article is initiated by building an illustrative simulation of the discussed wind energy system consisting of developed MSC \& GSC models, while using Wind turbine, three-phase, 2MW Asynchronous Machine, Transformer, Universal Converters, RLC load and grid from Simpower Systems toolbox of MATLAB/Simulink R2017a. The specifications of the WECS have specified in Table I. The switching frequency for converters and other blocks is kept fixed at $4 \mathrm{kHz}$, which along with the grid frequency of $50 \mathrm{~Hz}$ and relation (23), leads to the sampling time of $5 \mu \mathrm{sec}$. The step-wise mathematical model for the wind speed under this profile is defined as:

$\mathrm{v}_{\mathrm{w}}= \begin{cases}11 \mathrm{~m} / \mathrm{sec} & 0<\mathrm{t}<3 \mathrm{sec} \\ 8 \mathrm{~m} / \mathrm{sec} & 3<\mathrm{t}<6 \mathrm{sec} \\ 7 \mathrm{~m} / \mathrm{sec} & 6<\mathrm{t}<9 \mathrm{sec} \\ 9 \mathrm{~m} / \mathrm{sec} & 9<\mathrm{t}<12 \mathrm{sec} \\ 11 \mathrm{~m} / \mathrm{sec} & 12<\mathrm{t}<15 \mathrm{sec}\end{cases}$
For a fair comparison, the parameters of each controller are optimally tuned by TLBO technique with $\mathrm{a}_{1}=0.6$ and $\mathrm{a}_{2}$ $=0.4$ (in (29)) with error defined between optimum and actual rotor speed in with step-wise wind profile for a fractional span of 5.99 seconds out of the total simulation period of 15 seconds with 50 iterations. The fitness function value variation for each controller is shown in fig. 6. The tuning bounds of PID and NPID controllers are identical and determined after a coarse tuning manually. Table II provides the results of TLBO optimization carried out for the case study.

If a performance index to compare the effective tracking response of extant and proposed controller is defined as:

TABLE I. 2MW GRID-CONNECTED DFIG WECS PARAMETERS

\begin{tabular}{|l|c|c|}
\hline \multicolumn{3}{|c|}{ Wind Turbine Parameters } \\
\hline Parameters & Abbreviation & Value \\
\hline Rir Density & $\mathrm{P}_{\mathrm{tr}}$ & $2.067 \mathrm{MW}$ \\
\hline Radius of Swept Area & $\rho$ & $1.225 \mathrm{~kg} / \mathrm{m}^{3}$ \\
\hline Rated wind speed & $\mathrm{R}$ & 41 \\
\hline Pitch angle & $\mathrm{V}_{\mathrm{wr}}$ & $11 \mathrm{~m} / \mathrm{sec}$ \\
\hline \multicolumn{2}{|c|}{ DFIG Parameters } \\
\hline Rated Power & $\mathrm{P}_{\mathrm{gr}}$ & $2 \mathrm{MW}$ \\
\hline Rated Stator Voltage & $\mathrm{V}_{\mathrm{s}}$ & $690 \mathrm{~V}$ \\
\hline Rated rotor speed & $\omega_{\mathrm{gr}}$ & $217.3 \mathrm{rad} / \mathrm{sec}$ \\
\hline Pole pairs & $\mathrm{p}$ & 2 \\
\hline $\begin{array}{c}\text { Output frequency } \\
\text { Stator \& Rotor winding } \\
\text { resistance }\end{array}$ & $\mathrm{f}$ & $50 \mathrm{~Hz}$ \\
\hline $\begin{array}{c}\text { Mutual Inductance } \\
\text { (n) }\end{array}$ & $\mathrm{L}_{\mathrm{r}}$ & $2.6 \times 10^{-3} \Omega$ \\
\hline
\end{tabular}


TABLE II. PERFORMANCE COMPARISON OF PROPOSED VS EXTANT CONTROLLERS

\begin{tabular}{|l|c|c|}
\hline \multicolumn{3}{|c|}{ Fitness function-based performance indices } \\
\hline Controllers & $\begin{array}{c}\text { No. of iterations } \\
\text { taken to } \\
\text { converge }\end{array}$ & $\begin{array}{c}\text { Fitness } \\
\text { function } \\
\text { value }\end{array}$ \\
\hline PID & 30 & 1.2488 \\
\hline NPID & 25 & 0.80383 \\
\hline $\begin{array}{l}\text { Fuzzy-supervised PID } \\
\text { (f-PID) }\end{array}$ & $\mathbf{1 4}$ & $\mathbf{0 . 6 9 3 4 7}$ \\
\hline
\end{tabular}

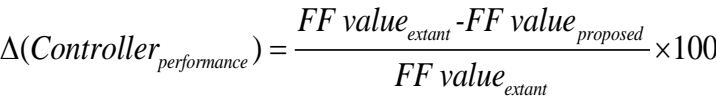

and with the PID controller referred to as the extant controller, it could be observed that the NPID controller outperforms PID by $35.632 \%$ whereas fuzzy-supervised PID outperforms PID by $44.469 \%$.

Fig. 7a shows the performance of the equation-based wind estimation block with respect to actual wind speed. Notice that the overshoot in the transition instant is due to the cubic root calculation, which will not affect the MPPT performance as the variation in rotor angular speed in such short transition will be negligible due to very high inertia of a $2 \mathrm{MW}$ based wind energy system. The tracking capabilities of the proposed and extant controllers can be measured and compared via DFIG mechanical power output with respect to its reference value as recorded using Fig. 7 and Table III. Please note that Error (err) is approximately measured once the power reached a steadystate, as close as possible to its reference value (recorded as settling time Ts). Fig. 7(b) verifies the superior performance of the proposed f-PID controller around all instances in terms of steady-state error and/or settling time. It can be observed that during some instants (Fig. 7(b) - instance A), Besides providing poor MPPT performance, the extant PID controller is found to be unsuccessful in tracking the reference value till the transition relaxation period is completed. This shortcoming will majorly affect the operation in real-world installation, especially when sudden variation in wind speed is experienced. If table 3 is observed, especially during instances $A \& C$, we can conclude with the fact that NPID has inferior performances as compared to that of f-PID as the Maximum power point (MPP) is achieved around 0.08-0.365 seconds faster in case of f-PID with the steady-state error difference in the range of 4-9 $\mathrm{kW}$, in the favor of the proposed controller.

There are some instances in the case study (Instance B), where the NPID controller does achieve MPP faster, however, the steady-state error corresponding to NPID is over $670.4 \mathrm{~kW}$ greater than that recorded for the proposed fuzzy supervised PID controller. With careful consideration of the cumulative of such poor efficiency over the extended time period, it can be concluded that the proposed controller does provide superior MPPT performance than the extant controllers in such instances as well.

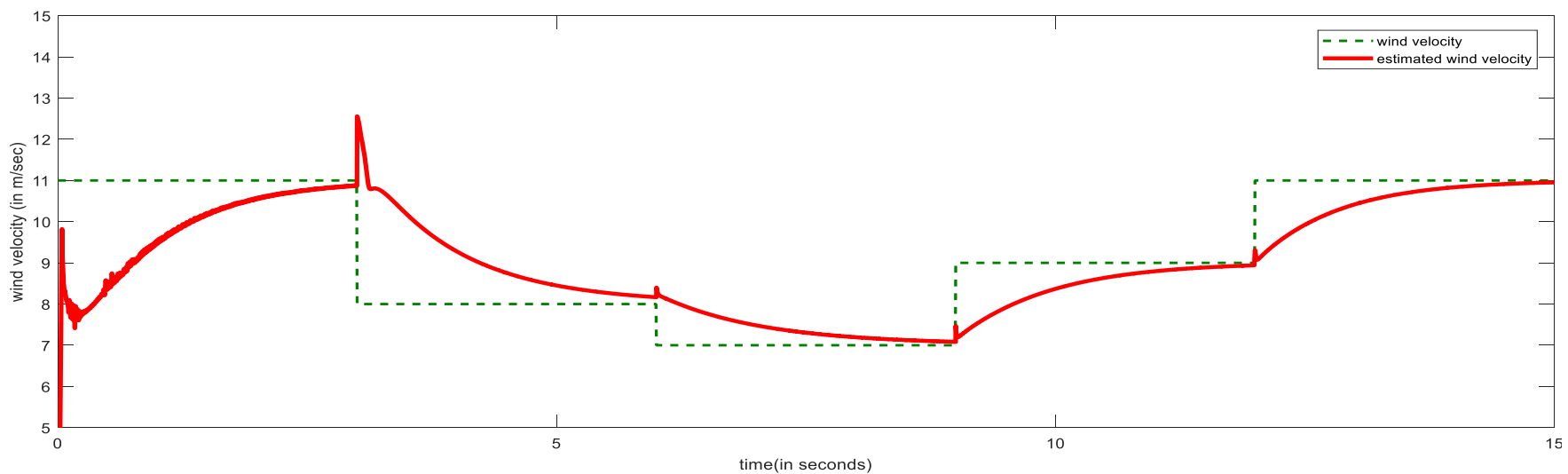

(a)

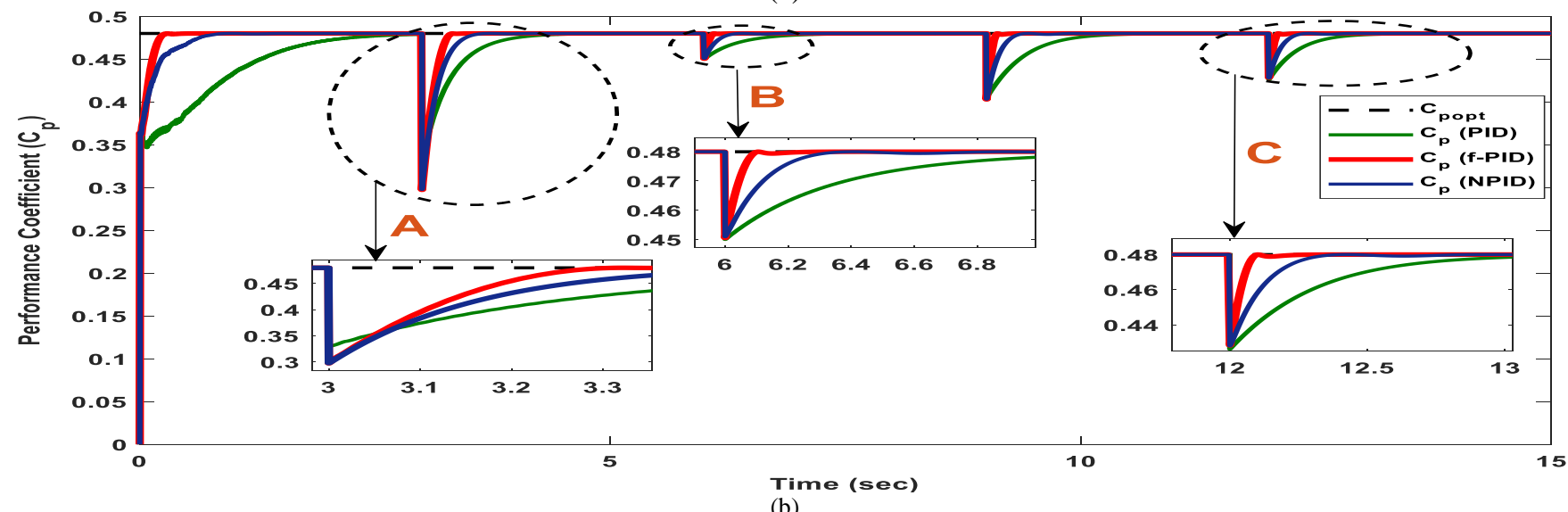




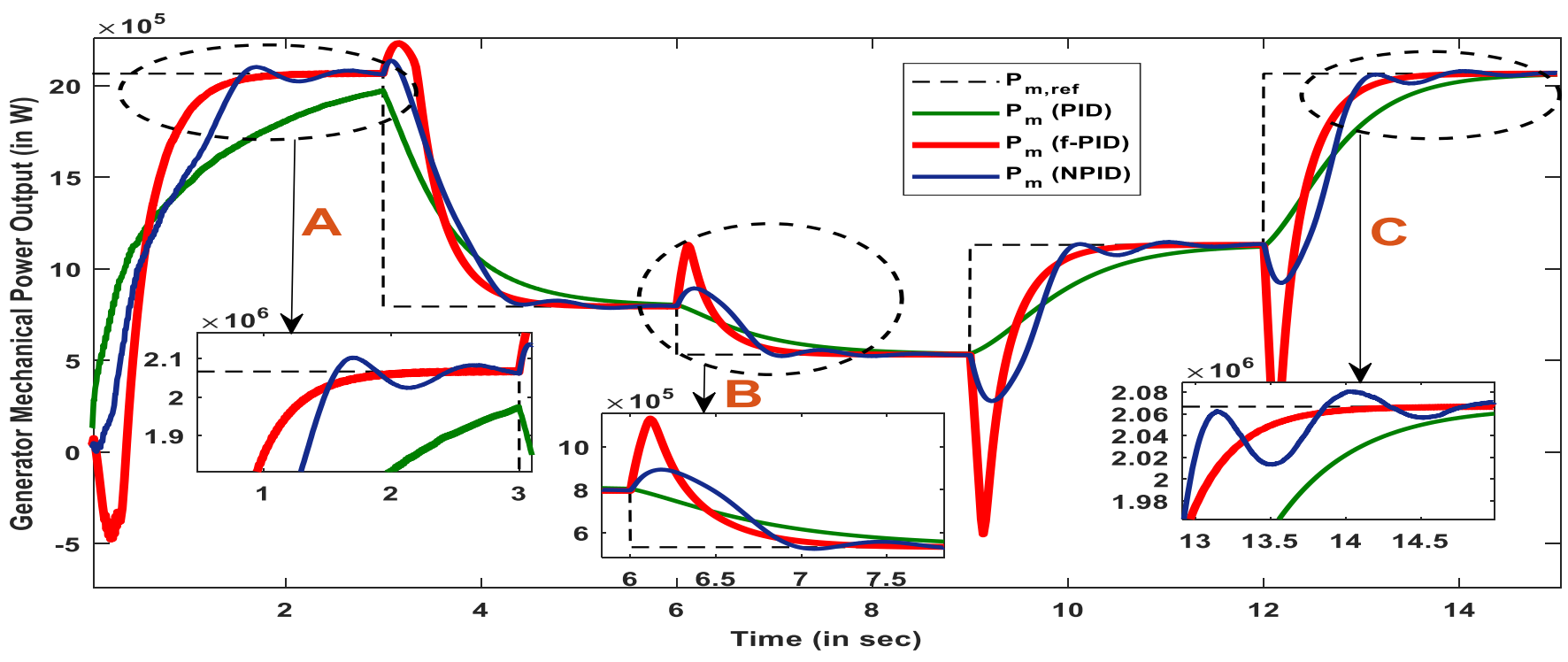

(c)

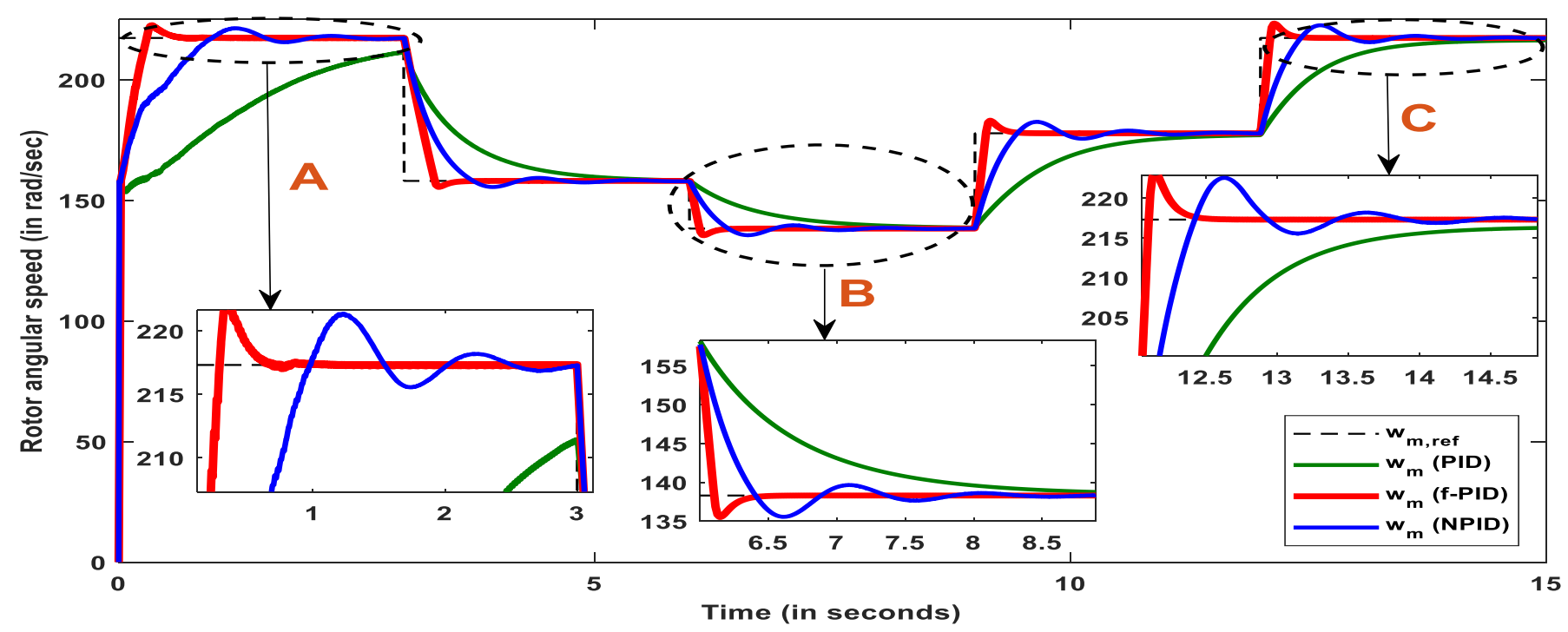

(d)

Fig. 7. (a) Wind estimation block response and MPPT Performance of proposed (NPID and fuzzy supervised PID) in comparison to extant (PID) in terms of (b) $C_{p}(c) P_{m}(d) \omega_{m}$

TABLE III. MPPT PERFORMANCE INDICES COMPARISON FOR EXTANT AND PROPOSED CONTROLLER

\begin{tabular}{|l|c|c|c|c|c|c|}
\hline \multicolumn{7}{|c|}{ Performance summary of MPPT controllers } \\
\hline \multirow{2}{*}{ Controller } & \multicolumn{2}{|c|}{ Instance $\boldsymbol{A}$} & \multicolumn{2}{|c|}{ Instance $\boldsymbol{B}$} & \multicolumn{2}{|c|}{ Instance $\boldsymbol{C}$} \\
\cline { 2 - 7 } & $\begin{array}{c}\mathrm{err} \\
(\mathrm{MW})\end{array}$ & $\begin{array}{c}\mathrm{T}_{\mathrm{s}} \\
(\mathrm{sec})\end{array}$ & $\begin{array}{c}\mathrm{err} \\
(\mathrm{MW})\end{array}$ & $\begin{array}{c}\mathrm{T}_{\mathrm{s}} \\
(\mathrm{sec})\end{array}$ & $\begin{array}{c}\mathrm{err} \\
(\mathrm{MW})\end{array}$ & $\begin{array}{c}\mathrm{T}_{\mathrm{s}} \\
(\mathrm{sec})\end{array}$ \\
\hline PID & 0.092 & - & 0.804 & 2.42 & 0.015 & 2.56 \\
\hline NPID & 0.01 & 2.44 & 0.693 & 1.33 & 0.007 & 2.39 \\
\hline f-PID & $\mathbf{0 . 0 0 1}$ & $\mathbf{2 . 0 7}$ & $\mathbf{0 . 0 2 2 6}$ & $\mathbf{1 . 4 6}$ & $\mathbf{0 . 0 0 3}$ & $\mathbf{2 . 3 1}$ \\
\hline
\end{tabular}

Fig. 8 shows the FFT analysis of A-phase grid current generated by the DFIG wind energy system at $t=4$ sec., i.e., just $1 \mathrm{sec}$. after the first transient in the wind speed is introduced. With analysis being done over 5 cycles of the current waveform, it can be observed that the THD content of DFIG response when the third harmonic injection is not applied, is greater than the condition where it is applied by $2.03 \%$. The THD content associated with the third harmonic component is suppressed by $92.272 \%$, with the modified SPWM generator and hence, it shows the effect of third harmonic injection into the conventional RSC module of the DFIG based wind energy system. 

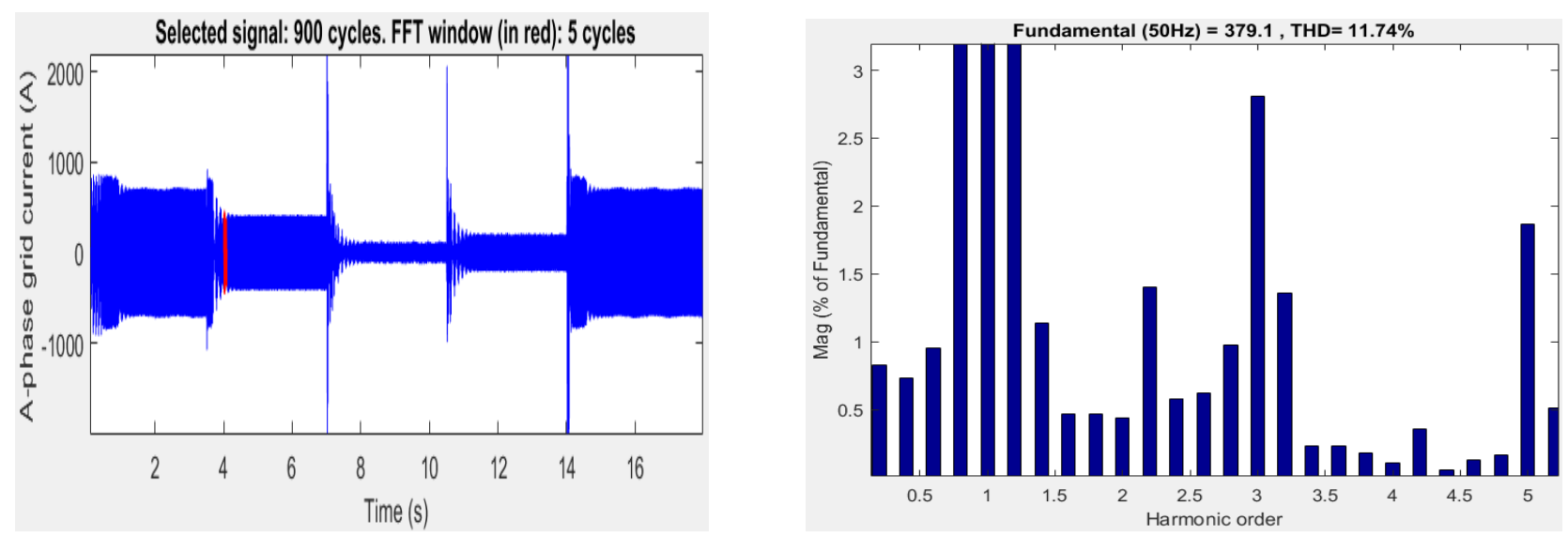

(a)
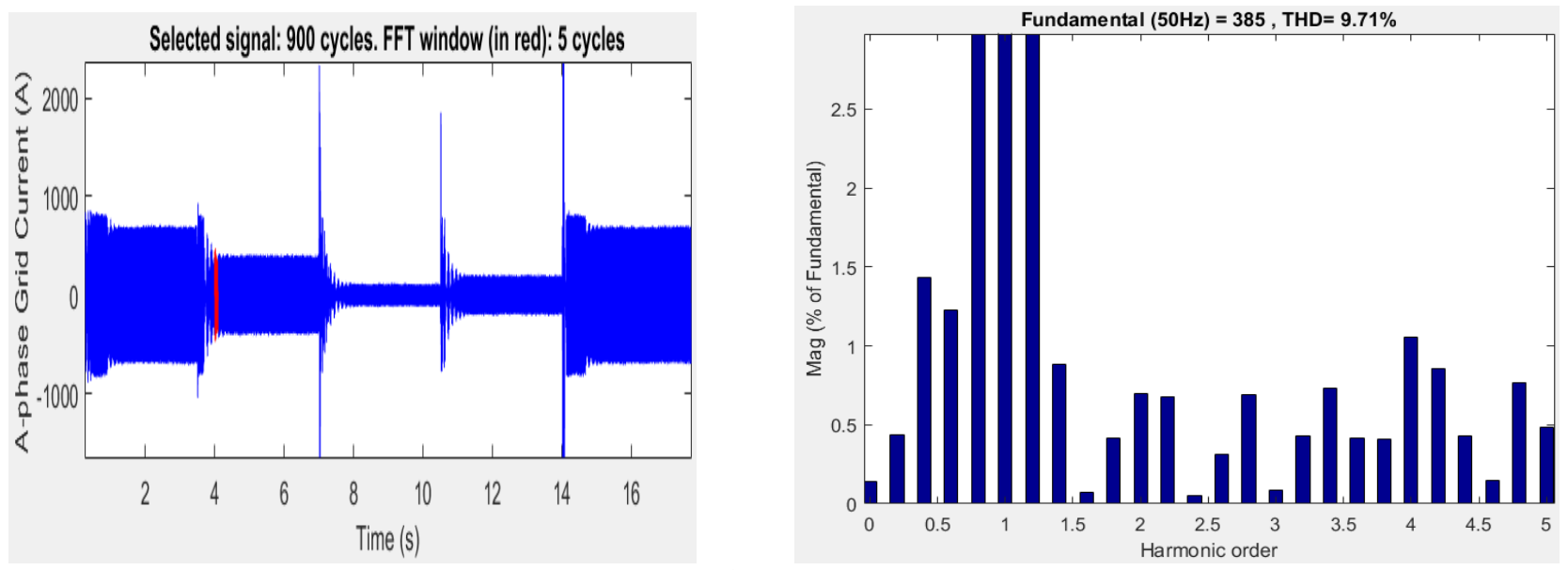

Fig. 8. Simulink based FFT Analysis of phase-A grid current (a) Without and (b) With modified SPWM generator with third harmonic injection

\section{CONCLUSION}

A grid-connected DFIG based WECS is simulated to verify superior performance of proposed fuzzy-supervised MPPT controller over the conventional and/or extant PID and NPID-based methods. Along with the MPPT enhancements, few other modifications are made to further improve the conventional Rotor side control (RSC) response when sudden variation in wind speed is experienced. First, the conventional PWM generator in the RSC is replaced with the modified SPWM generator with third harmonic injection algorithm to suppress THD content in the terminal current of the wind energy system. Secondly, to reduce installation cost and avoid sluggish, inefficient MPPT action, due to inaccurate measurement of wind speed via mechanically operated anemometer sensor, an equation-based wind speed estimation block is implemented to predict variation in wind velocity via generator-based voltage and current signals.

In the proposed MPPT method, variation in rotor speed and rate of change of the speed are sensed to compute reference torque when wind velocity varies. This parameter is then transformed into the rotor quadrature axis reference current, which is then fed to the modified vector control-based
RSC module to regulate active power generated. Simulation with step-wise wind profile is carried out to access the performance of discussed controllers in a fixed operational duration. The gain parameters of the extant as well as the proposed controllers are tuned fairly using a GA-based TLBO technique. Optimization results reveal that the f-PID controller has superiority over extant PID and proposed NPID based controllers in terms of dynamic MPP tracking and steady-state error by $44.469 \%$ and $13.729 \%$ respectively.

The comparative analysis reveals that the fuzzy supervised PID (f-PID) controller outperforms the extant controller at every instant of operation, with steady-state tracking efficiency measured in terms of time taken to reach maximum power point (MPP). As per the data summarized in Table III, the proposed fuzzy supervised PID achieves MPP 9.766$39.669 \%$ faster than the extant PID controller.

An FFT analysis of A-phase grid current generated by DFIG wind energy system reveals that the modified SPWM generator with third harmonic injection is successful in suppressing THD content of the generator power at the rate of $2.03 \%$ greater than that of conventional PWM generator used in the DFIG based wind energy conversion system. 


\section{ACKNOWLEDGMENT}

The authors are extremely grateful to the Instrumentation and Control engineering department of Netaji Subhas University of Technology (NSUT), New Delhi for the support and excellent technical facilities provided to this research project through the Industrial Electronics Lab of the department.

\section{REFERENCES}

G. Sideratos and N. D. Hatziargyriou, "An advanced statistical method for wind power forecasting," IEEE Trans. Power Syst., vol. 22, no. 1, pp. 258-265, 2007, doi: 10.1109/TPWRS.2006.889078.

[2] G. P. Prajapat, N. Senroy, and I. N. Kar, "Modeling and impact of gear train backlash on performance of DFIG wind turbine system," Electr. Power Syst. Res., vol. 163, no. December 2017, pp. 356-364, 2018, doi: 10.1016/j.epsr.2018.07.006.

[3] F. Lan, L. Tao, J. Li, and Z. Yao, "An improved variable step hillclimbing searching algorithm for tracking maximum power point of wind power system," China Int. Conf. Electr. Distrib. CICED, vol. 2016-Septe, no. Ciced, pp. 10-13, 2016, doi: 10.1109/CICED.2016.7576333.

[4] H. H. H. Mousa, A. R. Youssef, and E. E. M. Mohamed, "Hybrid and adaptive sectors $\mathrm{P} \& \mathrm{O}$ MPPT algorithm based wind generation system," Renew. Energy, vol. 145, pp. 1412-1429, 2020, doi: 10.1016/j.renene.2019.06.078

[5] M. M. Rezaei, "A nonlinear maximum power point tracking technique for DFIG-based wind energy conversion systems," Eng. Sci. Technol. an Int. J., vol. 21, no. 5, pp. 901-908, 2018, doi: 10.1016/j.jestch.2018.07.005.

[6] Z. L. Zeng, G. H. Xu, Y. Zhao, and F. Xie, "Adaptive backstepping controller design for leveling control of an underwater platform based on joint space," J. Control Sci. Eng., vol. 2014, 2014, doi: 10.1155/2014/989717.

[7] A. Dida and D. Benattous, "Fuzzy logic based sensorless MPPT algorithm for wind turbine system driven DFIG," $3 r d$ Int. Conf Control. Eng. Inf. Technol. CEIT 2015, 2015, doi: 10.1109/CEIT.2015.7233139.

[8] M. Amer et al., "Active Power Control in Doubly Fed Induction Generator by Using PID Control Technique," vol. 4, no. 2, pp. 671676, 2013.

[9] S. Abdelmalek, L. Barazane, A. Larabi, and M. Bettayeb, "A novel scheme for current sensor faults diagnosis in the stator of a DFIG described by a T-S fuzzy model," Meas. J. Int. Meas. Confed., vol. 91, pp. 680-691, 2016, doi: 10.1016/j.measurement.2016.05.102.

[10] M. Özger, "Comparison of fuzzy inference systems for streamflow prediction," Hydrol. Sci. J., vol. 54, no. 2, pp. 261-273, 2009, doi: 10.1623/hysj.54.2.261.

[11] F. Amrane, A. Chaiba, and B. Francois, "Suitable power control based on type-2 fuzzy logic for wind-turbine dfig under hyposynchronous mode fed by multi-level converter," 2017 th Int. Conf Electr. Eng. - Boumerdes, ICEE-B 2017, vol. 2017-Janua, pp. 1-6, 2017, doi: 10.1109/ICEE-B.2017.8191983.

[12] B. E. Elnaghi and S. A. Selim, "Performance of double fed induction generator based wind turbine using Adaptive NeuroFuzzy Inference System,” Proc. 2017 IEEE Russ. Sect. Young Res. Electr. Electron. Eng. Conf. ElConRus 2017, no. m, pp. 808-813, 2017, doi: 10.1109/EIConRus.2017.7910681.
[13] F. Amrane and A. Chaiba, "A hybrid intelligent control based on DPC for grid-connected DFIG with a fixed switching frequency using MPPT strategy," 2015 4th Int. Conf. Electr. Eng. ICEE 2015 , no. 1, 2016, doi: 10.1109/INTEE.2015.7416678

[14] Y. Mokhtari and D. Rekioua, "High performance of Maximum Power Point Tracking Using Ant Colony algorithm in wind turbine," Renew. Energy, vol. 126, pp. 1055-1063, 2018, doi: 10.1016/j.renene.2018.03.049

[15] O. P. Bharti, R. K. Saket, and S. K. Nagar, "Controller design for doubly fed induction generator using particle swarm optimization technique," Renew. Energy, vol. 114, pp. 1394-1406, 2017, doi: 10.1016/j.renene.2017.06.061

[16] C. Sompracha, D. Jayaweera, and P. Tricoli, "Particle swarm optimisation technique to improve energy efficiency of doubly-fed induction generators for wind turbines," J. Eng., vol. 2019, no. 18, pp. 4890-4895, 2019, doi: 10.1049/joe.2018.9348

[17] S. Soued et al., "Experimental behaviour analysis for optimally controlled standalone DFIG system," IET Electr. Power Appl., vol. 13, no. 10, pp. 1462-1473, 2019, doi: 10.1049/iet-epa.2018.5648.

[18] T. A. Boghdady, M. M. Sayed, and E. E. Abu Elzahab, "Maximization of generated power from wind energy conversion system using a new evolutionary algorithm," Renew. Energy, vol. 99, pp. 631-646, 2016, doi: 10.1016/j.renene.2016.07.045

[19] K. Belmokhtar, M. L. Doumbia, and K. Agbossou, "Novel fuzzy logic based sensorless maximum power point tracking strategy for wind turbine systems driven DFIG (doubly-fed induction generator)," Energy, vol. 76, pp. 679-693, 2014, doi: 10.1016/j.energy.2014.08.066

[20] Gonzolo Abad, Jesús López, Miguel Rodríguez, Luis Marroyo, Grzegorz Iwanski, "Introduction to A Wind Energy Generation System" in Doubly Fed Induction Machine: Modeling and Control for Wind Energy Generation Applications, New Jersey, USA: Wiley-IEEE, 2011, pp. 75-116

[21] T. Haiyan, H. Wei, Y. Chi, X. Tian, L. Yan, and W. Yukun, "Impac of grid side converter of DFIG on sub-synchronous oscillation and its damping control," Asia-Pacific Power Energy Eng. Conf. APPEEC, vol. 2016-Decem, pp. 2127-2130, 2016, doi: 10.1109/APPEEC.2016.7779863.

[22] Y. Majdoub, A. Abbou, and M. Akherraz, "Variable Speed Control of DFIG-Wind Turbine with Wind Estimation," 2014.

[23] D. Pathak, G. Sagar, and P. Gaur, "An Application of Intelligent Non-linear Discrete-PID Controller for MPPT of PV System," Procedia Comput. Sci., vol. 167, no. 2019, pp. 1574-1583, 2020, doi: 10.1016/j.procs.2020.03.368.

[24] D. Kler, K. P. S. Rana, and V. Kumar, "A nonlinear PID controlle based novel maximum power point tracker for PV systems," $J$. Franklin Inst., vol. 355, no. 16, pp. 7827-7864, 2018, doi: 10.1016/j.jfranklin.2018.06.003

[25] R. Sharma, P. Gaur, and A. P. Mittal, "Design of two-layered fractional order fuzzy logic controllers applied to robotic manipulator with variable payload," Appl. Soft Comput. J., vol. 47, pp. 565-576, 2016, doi: 10.1016/j.asoc.2016.05.043.

[26] C. Wei, Z. Zhang, W. Qiao, and L. Qu, "An Adaptive NetworkBased Reinforcement Learning Method for MPPT Control of PMSG Wind Energy Conversion Systems," IEEE Trans. Power Electron. vol. 31, no. 11, pp. 7837-7848, 2016, doi: 10.1109/TPEL.2016.2514370. 